\title{
NUMERICAL METHODS FOR THE FATIGUE ASSESSMENT OF WELDED JOINTS: INFLUENCE OF MISALIGNMENT AND GEOMETRIC WELD IMPERFECTIONS
}

\author{
Andreas TARAS ${ }^{\mathrm{a}}$, Harald UNTERWEGER ${ }^{\mathrm{b}}$ \\ ${ }^{a}$ Institute of Structural Engin., Bundeswehr University Munich, Werner-Heisenberg-Weg 38, \\ 85577 Neubiberg, Germany \\ ${ }^{b}$ Institute for Steel Structures, Graz University of Technology, Lessingstraße 25, 8010 Graz, Austria
}

Received 28 September 2016; accepted 04 November 2016

\begin{abstract}
The fatigue design life of welded joints in steel structures is increasingly assessed by using numerical models and methods, such as the structural (hot-spot) stress method and the effective notch stress method. When compared to the classical design approach using nominal stress S-N design curves, these methods offer the advantage of flexibility and a wider scope of application. However, a number of questions arise when these methods are used to assess geometrically "imperfect" welded joints, such as joints with plate misalignments or excessive weld convexity or concavity. In these cases, the classical S-N curves are known to cover imperfections up to the common tolerance classes for fatigue-prone welded joints (e.g. in accordance with ISO 5817 class B). For the numerical methods, differing and conflicting recommendations exist on how to account for the geometric imperfections in the welded joints, with little or no background to these recommendations available. In this paper, a study is presented in which two standard welded joints (butt welds between plates of equal and unequal thickness; T-joints with fillet welds) are analysed with the help of the structural (hot-spot) stress and the effective notch stress approach, considering various levels of geometric imperfection up to the tolerance limits, and the resulting fatigue life predictions are compared to test results from the literature and the nominal stress approach predictions. Since the nominal stress approach curves are based on reliable statistical data and desired survival probabilities for these known, standard cases, this methodology allows one to determine the correct application of the numerical methods to cases with geometric imperfections. This information may be used for a pertinent refinement of design recommendations for these methods, as well as for cases where these methods are applied to fitness-for-purpose assessments e.g. because the nominal stress approach is not applicable.
\end{abstract}

Keywords: fatigue design, numerical fatigue stress calculation, misalignment, weld imperfections, standardization, Eurocode 3 part 1-9.

\section{Introduction: Fatigue Design Methods, FAT classes, $\mathrm{S}-\mathrm{N}$ curves}

Stress calculations using Finite Element Method (FEM) modelling and analysis techniques are increasingly common in the assessment and design of welded joints against fatigue failure. The possibility of realistically representing the geometry of the weld, as well as the surrounding joint area, thereby eliminates a large amount of the uncertainty inherent in the traditional design approaches for fatigue, which are based on beam-theoretical, nominal stresses in the vicinity of the welded joint, but do not reflect the actual stress state at the joint.

In the traditional method, called the nominal stress approach in the literature, the differences in fatigue performance between the multitude of possible

Corresponding author:

A. Taras E-mail: andreas.taras@unibw.de 
welded joints is accounted for by the use of a catalogue of structural detail classes (FAT classes), each pertaining to a different stress-load cycle curve (known as "S-N curve"). Such a catalogue of FAT classes and S-N curves is e.g. contained in Eurocode 3 (EN 1993-19:2005). The different S-N curves in Eurocode 3 are based on testing of full-scale welded components and joints, and represent a survival probability of $95 \%$.

In the more advanced, numerical methods, stresses are calculated in the immediate vicinity of, or directly at, the weld, on the basis of a realistic model of the theoretical weld geometry. Due to the more precise representation of the global geometrical stress raising effects, the stress calculation in these methods already accounts for the most relevant sources of differences between the fatigue performance of various structural details, and thus largely eliminates the need for the consideration of different FAT classes. For this reason, when applying the structural stress and effective notch stress numerical methods of fatigue stress calculation, which are described in section 3 , it is possible to consider fewer FAT classes for each method, and for all detail configurations. This is shown in Figure 1, where five S-N curves in the shape of the Eurocode 3 curves are plotted.

Thereby, FAT 225 illustrates the single S-N curve to be used for all welded steel details when applying the effective notch stress method according to the IIW recommendation (Hobbacher 2016). When applying the structural stress method, FAT 100 may be used for weld toes in all butt welds, while FAT 90 may be used for weld toes in cruciform joints. The other two lines, FAT 80 and 36, as well as once more FAT 90, represent the nominal stress FAT classes for the different studied details. The FAT class carries the designation that corresponds to the fatigue strength, in terms of stress am-

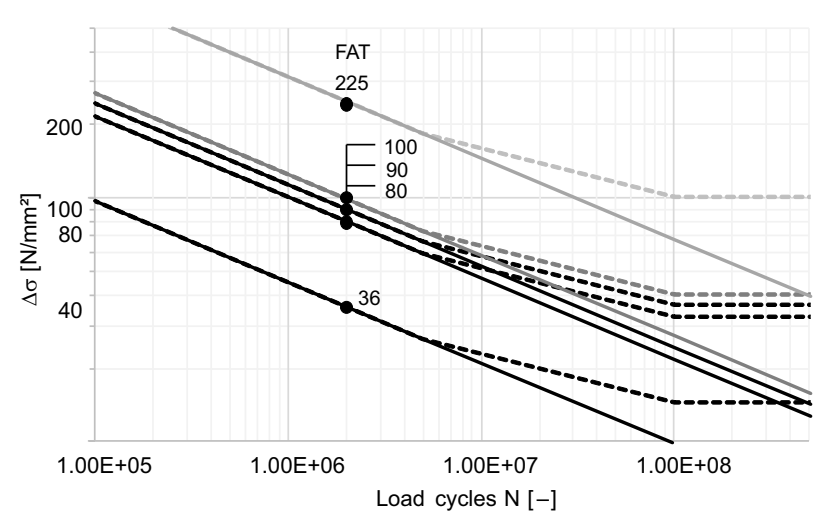

Fig. 1. Simplified S-N fatigue design and assessment curves considered in this study (fatigue limit $\Delta \sigma_{D}$ ignored) plitude $\Delta \sigma_{c}$, that corresponds to a fatigue life of $\mathrm{N}=2$ million load cycles. The continuous lines in the figure show S-N curves with a constant slope (in the doublelogarithmic scale) of $m=-3$, while the dashed lines show the shape of the curves valid for non-constant amplitude fatigue loading, with slope changes due to the reduced damage effect of of small stress cycles (Maddox 1991). The different FAT classes used for the three methods and for the welded details considered in this study are summarized in Table 1.

\section{Motivation - misalignment, geometric weld imperfections and their effect on fatigue design}

\subsection{General remarks}

Welded joints are inevitably fabricated with a certain degree of geometric shape deviation and imperfection. Among these, the linear misalignment " $\mathrm{e}$ " of the centre lines of the joined plates is among the most relevant. Additionally, the weld geometry itself must fulfil certain geometric criteria, in accordance with specific fabrication and design code requirements. Weld imperfections are classified in different "quality levels" in ISO 5817:2014. The Eurocode 3 nominal stress FAT classes generally refer to the requirements of EN 1090-2:2009 for the "execution class" EXC 3, which in turn makes reference to the weld imperfection quality level "B" of ISO 5817. Thus, for welded joints designed against fatigue, it can be assumed that this quality level must be fulfilled. Figure 2 shows the corresponding level "B" maximum permissible values of misalignment and weld geometry parameters for the considered types of imperfection in butt welds.

In some welded details, the FAT class catalogues for the nominal stress approach of either Eurocode 3 or of the IIW recommendation contain additional geometric requirements, which exceed the requirements of ISO 5817 level "B". These additional requirements are mentioned in the right-hand column in Table 1. For example, for butt welds the Eurocode / IIW FAT class 90 can only be applied if the value of misalignment is smaller than $5 \%$ of the plate thickness, and if the excess weld height $h$ is smaller than $10 \%$ of the maximum weld opening width $b$; both criteria are stricter than the ISO 5817 level "B" requirements. The nominal FAT class 80, on the other hand, can be applied when the criteria of ISO 5817 level "B" are met - without any further restrictions; in fact, the value of the excess weld height $h$ of $20 \%$ of $b$ mentioned in Eurocode 3 is less strict than the ISO 5817 level "B" requirement for values of $b$ exceeding $10 \mathrm{~mm}$. 
Table 1. FAT classes for the various fatigue design approaches and specific geometric requirements for the nominal stress approach

\begin{tabular}{|c|c|c|c|c|}
\hline Welded detail & $\begin{array}{l}\text { Nominal stress } \\
\text { FAT class } \\
\hat{=} \Delta \sigma_{\mathrm{c}}\left[\mathrm{N} / \mathrm{mm}^{2}\right]\end{array}$ & \begin{tabular}{|c|} 
Structural stress \\
FAT class \\
$\hat{=} \Delta \sigma_{\mathrm{c}}$ \\
{$\left[\mathrm{N} / \mathrm{mm}^{2}\right]$} \\
\end{tabular} & $\begin{array}{c}\text { Effective notch } \\
\text { stress } \\
\text { FAT class } \\
\hat{=} \Delta \sigma_{\mathrm{c}}\left[\mathrm{N} / \mathrm{mm}^{2}\right] \\
\end{array}$ & $\begin{array}{l}\text { Specific geometric requirements } \\
\text { for nominal stress approach }\end{array}$ \\
\hline $\begin{array}{l}\text { Butt weld, not ground flush, } \\
\text { stricter geometry }\end{array}$ & 90 & \multirow{2}{*}{100} & \multirow{4}{*}{225} & $\begin{array}{l}\text { From EN 1090-2 - EXC 3: } \\
\text { ISO } 5817 \text { level B } \\
\text { From Eurocode 3: see figure on the left } \\
\text { for excess weld metal height } h \\
\text { From IIW: misalignment e } \leq 0.05 \mathrm{t} \\
\text { "Class B-Fatigue" }\end{array}$ \\
\hline $\begin{array}{l}\text { Butt weld, not ground flush, } \\
\text { more permissible geometry }\end{array}$ & 80 & & & $\begin{array}{l}\text { From EN 1090-2 - EXC 3: } \\
\text { ISO } 5817 \text { level B } \\
\text { From Eurocode 3: excess weld metal } \\
\text { height h in figure on the left is less strict } \\
\text { than ISO } 5817 \text { level B } \rightarrow \text { not relevant! } \\
\text { From IIW: misalignment e } \leq 0.1 \mathrm{t} \\
\text { "Class B" }\end{array}$ \\
\hline $\begin{array}{l}\text { Cruciform joint, } 1 \leq 50 \mathrm{~mm} \text {, } \\
\text { crack from weld toe }\end{array}$ & 80 & 90 & & $\begin{array}{l}\text { From EN 1090-2 - EXC 3: } \\
\text { ISO } 5817 \text { level B } \\
\text { From Eurocode } 3 \text { and IIW: } \\
\text { misalignment } \mathrm{e} \leq 0.15 \mathrm{t}\end{array}$ \\
\hline $\begin{array}{l}\text { Cruciform joint, crack from } \\
\text { weld root }\end{array}$ & 36 & Not applicable & & $\begin{array}{l}\text { From EN 1090-2 - EXC 3: } \\
\text { ISO } 5817 \text { level B } \\
\text { From Eurocode } 3 \text { and IIW: } \\
\text { misalignment e } \leq 0.15 \mathrm{t}\end{array}$ \\
\hline
\end{tabular}

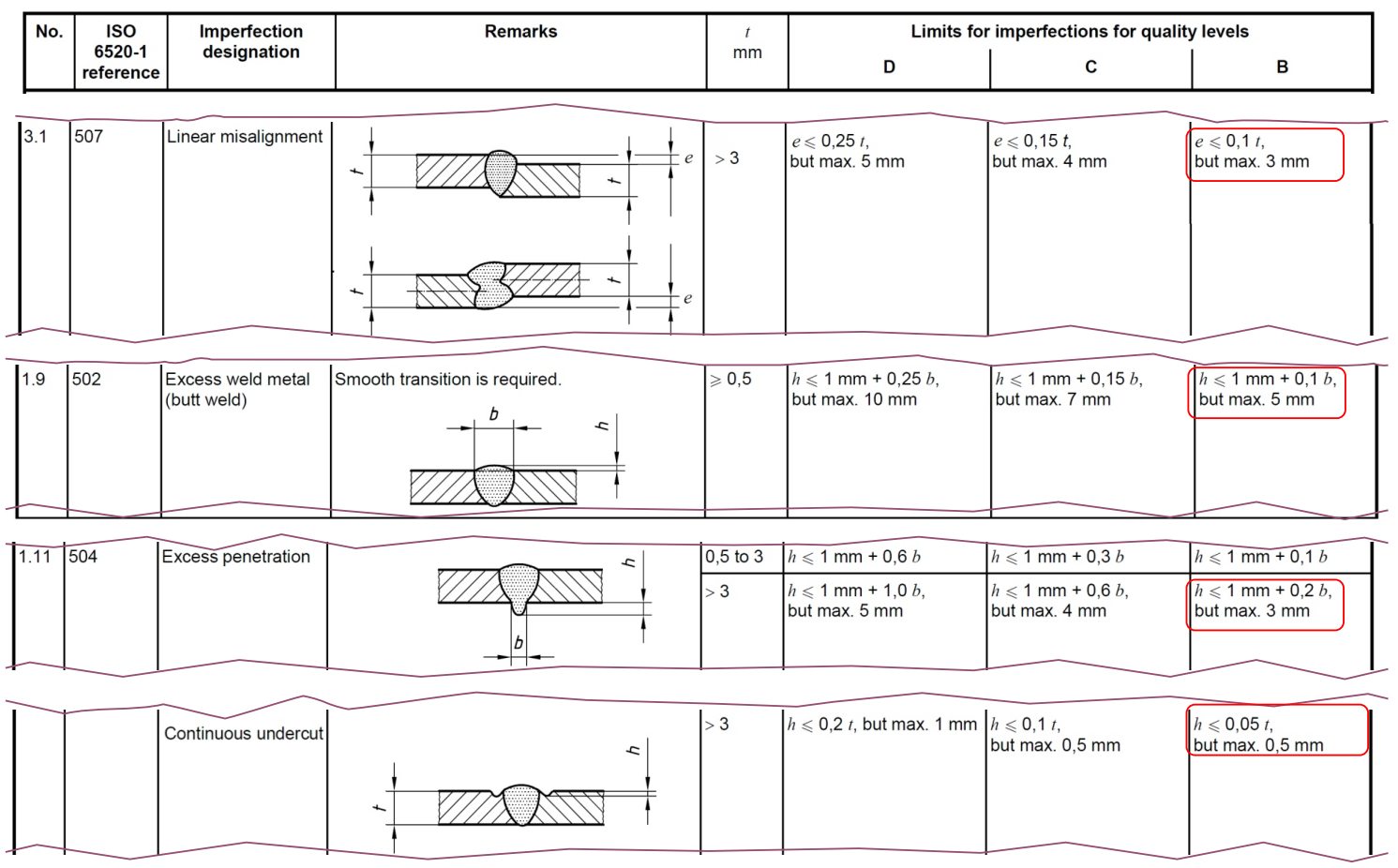

Fig. 2. Considered geometric weld imperfections for butt welds: a) linear misalignment; b) excess weld metal; c) excess root penetration; d) continuous undercut; class "B" tolerance limits according to ISO 5817:2015 are highlighted 
When applying the traditional nominal stress fatigue design approach, the influence of misalignment and other geometric weld imperfections is thus clearly accounted for in the choice of FAT class and corresponding S-N curve: it is assumed that the underlying test data population reflects the fatigue strength of welded joints with various values of imperfection, up to the specified limit values. The influence of the various levels of imperfection is thereby included in the scatter of the resistance values.

For the numerical fatigue design methods, i.e. the structural stress and effective notch stress methods, the effects of misalignment are not directly covered by the FAT classes. The IIW recommendation states that geometric stress raising effects due to misalignment of only up to $5 \%$ are included in the FAT classes for the structural and effective notch stress approach. Misalignment effects exceeding these values must be specifically accounted for in the numerical calculation, either $i$. directly in the analysis (by modelling both a perfectly aligned and an imperfect, misaligned joint and comparing the results), or ii. by applying appropriate stress modification factors $\mathrm{k}_{\mathrm{m}}$ (used as multipliers; $\left.k_{m} \geq 1.0\right)$ to the analysis results for the perfectly aligned system (Note: $\mathrm{k}_{\mathrm{m}}$ is the terminology of the IIW recommendation; Eurocode 3 uses $\mathrm{k}_{\mathrm{f}}$ for the same coefficient).

\subsection{Motivation, objectives and structure}

The study presented in this paper aimed at giving a detailed overview of the influence of misalignment on the stresses and on the fatigue life predictions obtained from FEM analyses in the context of the structural stress and effective notch stress approach. The goal of this analysis was to highlight the importance of the correct application of effective notch and structural stress approaches to simple, yet practically very

a) Butt welds

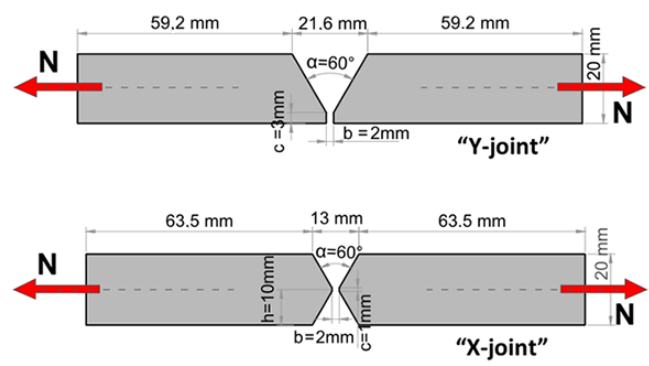

relevant welded joints, i.e. butt welds in flat plates and cruciform joints with fillet welds. This question is of great relevance to researchers and practitioners in the field of fatigue-critical steel structures, such as bridges, masts, cranes and other movable steel structures. The mentioned numerical methods are increasingly entering engineering practice in these fields, yet their validation is not complete and their codification, e.g. in Eurocode 3, is seen as lacking. This paper can thus be seen as a contribution to an on-going discussion in the civil engineering community on the correct application of the structural stress and effective notch stress methods. Since the focus of this paper is put on the effect of weld misalignment and other geometric imperfections, the results presented in this paper may be particularly helpful when these numerical methods are applied to fitness-for-purpose analyses of welds for which the specified tolerance limits are exceeded.

A section illustrating the considered joint geometries follows this introductory section. Then, the methodology used in the calculation of stresses in the two considered numerical methods is explained in section 3. Section 4 discusses the stress state and the results, in terms of stresses and calculated fatigue life values, for butt welds. In section 5 , a summary of similar results is given for cruciform joints. A discussion follows in section 6. Finally, conclusions are presented at the end of the paper.

\section{Scope of the study - considered joint geometries}

In order to highlight the most fundamental differences between the various design methods against fatigue of welded joints, including the long-established, traditional nominal stress method, two basic joint types were considered in this study, see Figure 3: butt welds (a) and cruciform joints with fillet welds (b). Since some of the tolerance limits for the geometric features

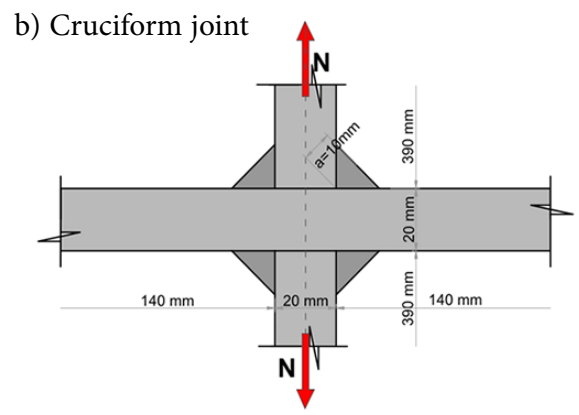

Fig. 3. Welded joint configurations studied in this paper 
of the welds are given in dependence of the geometry of the weld preparation, two different types of butt weld were considered: Y-joints, with a one-sided opening of the weld preparation, and $\mathrm{X}$-joints, with doublesided openings - each time with $\alpha=60^{\circ}$ and with a pre-welding gap of width $b=2 \mathrm{~mm}$ between the plates before welding.

For simplicity, only one plate thickness, in a thickness range that is quite typical for welded plate girders, was considered for all joints, with $\mathrm{t}=20 \mathrm{~mm}$. The plates were considered to be loaded in the tension range, as shown in the figure. It shall be noted that stresses $\sigma$ and stress amplitudes $\Delta \sigma$ can be treated as equivalent for the purposes of this study, since the basic, constant amplitude fatigue case is considered where a pulsating load is applied from zero up to the maximum load, i.e. $\Delta \sigma \hat{=} \sigma$. For a simpler comparison, only stresses above the constant amplitude fatigue limit $\Delta \sigma_{\mathrm{D}}$ were considered.

\section{Methodology: FEM discretization and stress calculation}

As stated in the introduction, the structural stress and the effective notch stress method require the use of numerical (usually: FEM) modelling and analysis techniques. In the following, the modelling, discretization and stress retrieval methods for the respective methods are discussed.

\subsection{Effective notch stress method}

Of the two numerical fatigue design methods considered in this paper, the effective notch stress method is the one which requires by far the highest degree of mesh refinement. In fact, in this method localized stresses are calculated directly at the presumed, critical geometric weld notch for the fatigue design. Following the theoretical derivations (on the basis of the Neuber rule) and developments of Radaj et al. (2006), in this method the "real" geometric notch is replaced by a notch rounding radius of $\mathrm{r}=1 \mathrm{~mm}$, see Figure 4; for further references, see also (Fricke 2010; Hobbacher 2016). The mesh sensitivity of this method is discussed by Radaj, and some recommendations are given in the IIW rules (Hobbacher 2016). The mesh sizing shown in Figure 4 corresponds to the IIW recommendations for 4-node, isoparametric linear elements.

Whether von Mises or principal stresses should be considered is not clearly specified in the IIW recommendation. Following the recommendation of Sonsino (2009), the effective notch stresses were calculated as maximum principal stresses at the effective notch in this study.

The simple details considered in this study could be analysed with the help of plane stress elements, hugely increasing computational efficiency; this was justified by the common presence of elements of limited width in plated steel girders. For reasons of comparison, some models were also calculated using plane strain elements, as this case represents the other limiting case for uniform, planar joints. The differences in terms of effective notch stresses and calculated fatigue life values were negligible for the purposes of this study.

\subsection{Structural (hot-spot) stress method}

The structural stress method (also known as the hotspot stress method) was originally developed for the offshore structures sector, in particular for the fatigue design of welded joints in tubular structures, see e.g. (Lotsberg 1998, 2006). Structural stresses are
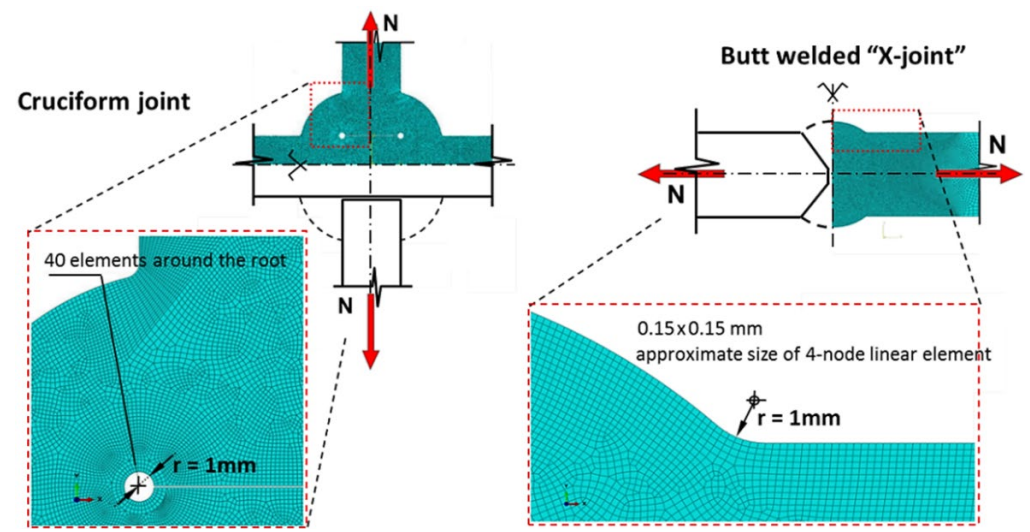

Fig. 4. FEM mesh for stress calculations according to the effective notch stress method 
defined as theoretical stresses on the plate surface at the considered weld toe, which account for the plate membrane and bending stresses, but not additional, non-linear stress components. The idea behind the method is to make use of stresses that account for the geometric stress raising effects of the geometry of the larger joint area - yet not of the local weld geometry itself. These stresses may still be easily measured (e.g. through strain gauges), and are equal to nominal stresses in the case of "weak" notches in welded details, e.g. in welded plates of equal thickness where the welds were ground flush.

Many definitions of structural stresses exist in the literature, see e.g. Radaj et al. (2006). A recent, comparative study of the various definitions of structural stress, as well as the use of the effective notch stress method for bridge details, was provided by Aygül et al. (2013). Of the possible definitions for the calculation of structural stresses, the one shown in Figure 5 was used in this paper: a linear extrapolation of the surface stresses calculated at a distance of $0.4 \mathrm{t}$ and $1.0 \mathrm{t}$ from the weld toe.

It shall be noted that the same FEM mesh as for the effective notch stress method was used for the structural stress method; this procedure is not commonly applied in practice, as much coarser meshes may be used in this case, even consisting of a single (quadratic) element across the plate thickness. However, the procedure appears justified in the given case, where a pure comparison of methods is carried out, and is also compatible with the fact that the same structural stress definition may also be used in physical strain measurements using strain gauges.

\section{Results for butt-welded joints}

The main focus of this paper is placed on the behaviour of butt-welded joints. In the following sub-sections, firstly the general stress-raising effect of misalignment in flat, butt-welded plates is discussed. Secondly, the general differences in stress calculation according to the different methods and recommendations are discussed. Finally, the results of the numerical study are shown in terms of calculated fatigue life values for the different methods and their comparison.

\subsection{Stress raising effect of misalignment - stress concentration factors $\mathrm{k}_{\mathrm{m}}$}

Misalignment between the centre lines of flat plates causes a bending moment in the plates, due to the eccentricity of the force path and the resulting force couple. In reality, the amount of bending moment to be transferred in the joint is not only a function of the eccentricity e, but also of the structural system underlying the calculation. In this study, as well as in the hand formulae for $\mathrm{k}_{\mathrm{m}}$ factors for the consideration of misalignment in the IIW recommendation, only the simple system shown in Figure 6 is considered.

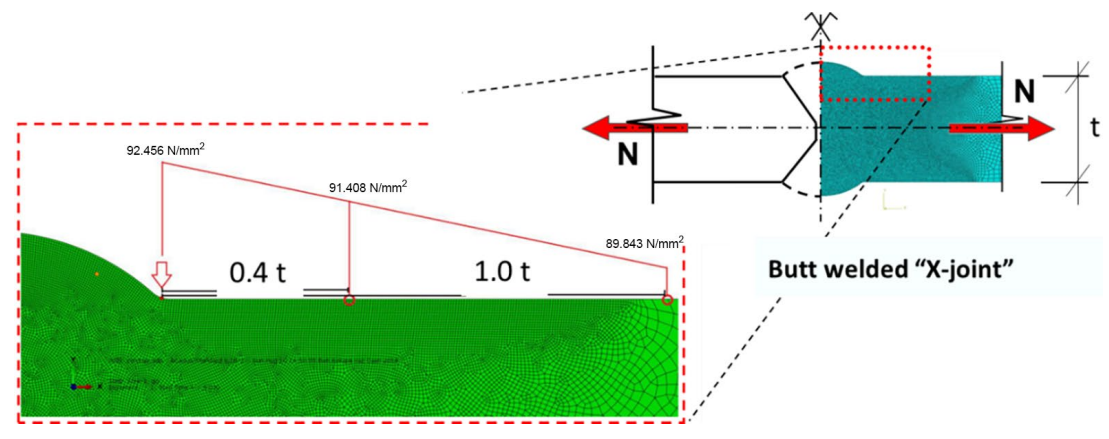

Fig. 5. Stress extrapolation for the structural hot-spot stress method

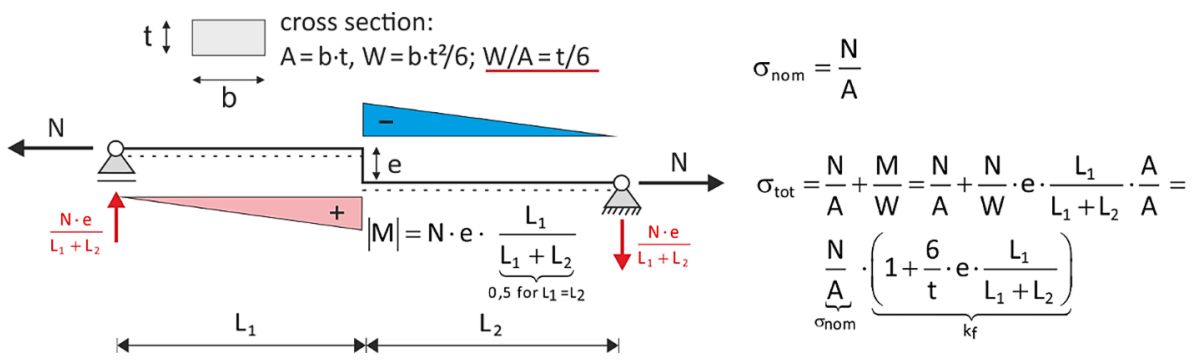

Fig. 6. Derivation of the IIW stress concentration factor $\mathrm{k}_{\mathrm{m}}$ for butt welds in plates of equal thickness 
The figure shows a simply supported tension bar with the misalignment (i.e. the imperfect butt weld) at the mid-length point. In this case, the bending moment on each side of the weld is equal to $\mathrm{N} \cdot \mathrm{e} \cdot \mathrm{L}_{1} /$ $\left(\mathrm{L}_{1}+\mathrm{L}_{2}\right)=\mathrm{N} \cdot \mathrm{e} \cdot 0.5$ for equal lengths $\mathrm{L}_{1}=\mathrm{L}_{2}$. The purely geometrical / structural stress raising factor due to eccentricity may thus be calculated as shown in the figure. It results in the following formula for the stress modification factor $\mathrm{k}_{\mathrm{m}}$ for this type of misalignment, found in the IIW recommendation:

$$
k_{m}=1+6 \cdot \frac{e}{t} \cdot{\frac{L_{1}}{L_{1}+L_{2}}}^{L_{1}=L_{2}}=1+3 \cdot \frac{e}{t} .
$$

This formula is intended to be applied to the structural and effective notch stresses when the misalignment is not explicitly accounted for in the numerical model. It may also be applied to stresses calculated with the nominal stress approach when assessing the fitnessfor-purpose of details that have misalignment values that exceed the geometrical tolerances and requirements, see Table 1 . However, in this case e should be replaced by a value of $\mathrm{e}^{\star}$, representing the difference between the tolerance limit and fabricated misalignment.

As stated above, the influence of the structural system should be kept in mind when applying this formula, even though this is not stated very explicitly in the IIW recommendation or the Eurocode. For example, if the misalignment occurred in a cantilever-type plate, with one end clamped and one end free, the factor $\mathrm{k}_{\mathrm{m}}$ would be $\mathrm{k}_{\mathrm{m}} 1+6 \mathrm{e} / \mathrm{t}$, instead of $1+3 \mathrm{e} / \mathrm{t}$ (moment $\mathrm{M}=\mathrm{N} \cdot \mathrm{e}$ instead of $\mathrm{M}=0.5 \mathrm{~N} \cdot \mathrm{e}$ ).

In the following, this simple expression is compared to the findings of the numerical study, with the aim of assessing the accuracy of the formulation itself, respectively the sensitivity to misalignment of the various critical weld toes in butt welds. Figure 7 contains the relevant results, which are plotted as stress ratios $\sigma_{\mathrm{hs}} / \sigma_{\mathrm{hs}, 0}$ respectively $\sigma_{\mathrm{en}} / \sigma_{\mathrm{en}, 0}$ over various values of the relative misalignment $e / t$. The index "hs" is used for the structural - or "hot-spot" - stresses, while "en" is used for the effective notch stresses. The hot-spot and effective notch stresses with a certain value of misalignment are related to the stresses calculated on the model without misalignment, indicated by the index " 0 ". These ratios can directly be compared to the IIW $\mathrm{k}_{\mathrm{m}}$ formula above, Eq. (1).

In all calculations illustrated in Figure 7, the butt weld geometry pertaining to the nominal FAT class 90 of Table 1 was considered, with all applicable weld imperfections of Figure 2; only the value of misalignment was varied beyond the actual tolerance for this detail, which would be limited to $e / t=0.05$, see Table 1 , righthand column. For the structural stress method, only the Y-joint configuration was considered (Fig. 7a), while for the effective notch stress method both the Y- (Fig. 7b) and $\mathrm{X}$-joint configuration (Fig. 7c) were looked at.

The results for the structural (hot-spot) stress method are predictably easy to interpret. In this case, the stress raising effect of misalignment in the most critical weld toes is very well, and slightly conservatively, described by Eq. (1); this is not surprising, given that the structural stress method operates with plate membrane and bending stresses (whereby here these components were calculated with some approximation, by applying the stress extrapolation shown in Fig. 5), yet omits non-linear stress components immediately at the weld toe. Thus, Eq. (1), which also only considers axial forces and bending moments, must be accurate.

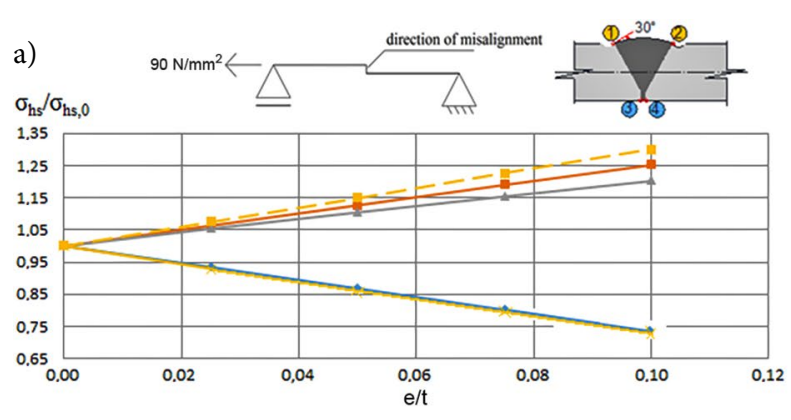

b)

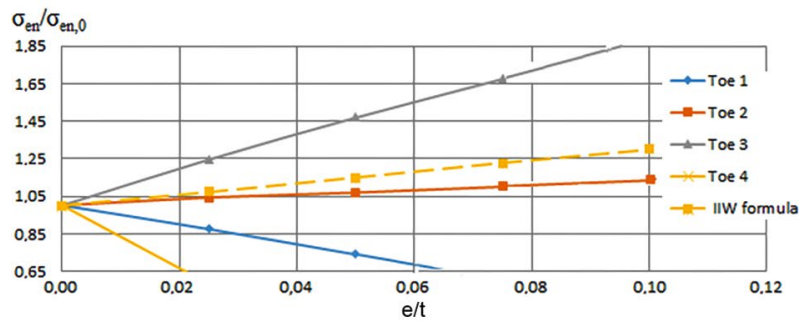

c)

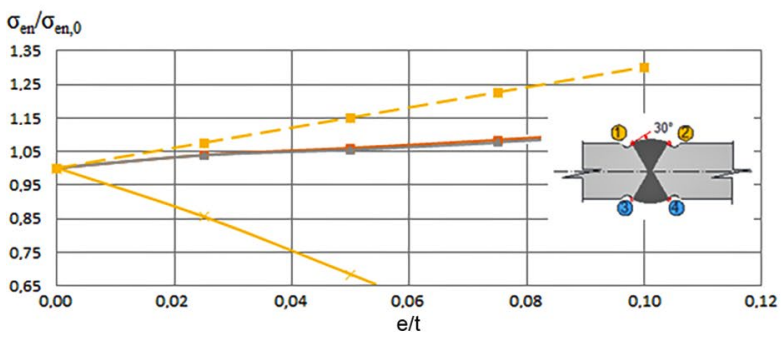

Fig. 7. Stress concentration factors $\mathrm{k}_{\mathrm{m} \hat{=}} \sigma_{\mathrm{hs}} / \sigma_{\mathrm{hs}, 0}$ and $\sigma_{\text {en }} /$ $\sigma_{\text {en, } 0}$ for increasing relative misalignment $\mathrm{e} / \mathrm{t}$ and for the hotspot stress and effective notch stress methods, respectively: a) structural (hot-spot) stress concentration factor for buttwelded Y-joints; b) effective notch stress concentration factor for butt-welded Y-joints; c) effective notch stress concentration factor for butt-welded X-joints 
The small differences can be attributed to the fact that the critical toes, 2 and 3, are not precisely in the centre line of the weld. This effect depends on the total length of the modelled plates, which was quite short in the considered models, see Figure 3. With longer total lengths, this effect would decrease. Furthermore, a certain degree of mesh dependency is given in this method. The fact that the weld toes 1 and 4 show decreasing stress "raising" ratios is also not surprising, given that these nodes are on the (beneficial) compression side of the misalignment bending moment.

In the results for the effective notch stress method (Fig. $7 \mathrm{~b}$ and $\mathrm{c}$ ), the linearity of the stress increases is still visible. However, the IIW formulation is no longer accurate and consistently safe-sided. In the case of the Y-joint in Figure 7b, the stress raising effect at toe 3 is much higher than the one predicted by the beam-theoretical Eq. (1), while the stresses at the other toes are smaller, in some cases very significantly. This behaviour can be attributed mostly to the fact that the weld root in this Y-shaped butt weld is very small, causing a very large geometric discontinuity if indeed the maximum values of ISO 5817 level "B" are considered for the root imperfection, see Figure 2. Thus, in this case the notch stresses at the on-set of the butt weld root is much higher than expected. In the case of the X-joint in Figure 7c, however, the opposite effect applies: in this case, the stresses at all weld toes (which are now symmetrical) are lower than what would be predicted by the IIW formula (Eq. (1)). Again, this can be attributed mostly to the fact that the weld toes are not precisely in the middle of the weld. It is also interesting to note that the toes on the compression side for bending (toe 1 and 4 ) feature a stronger decrease of the stress ratio than the corresponding increase in toes 3 and 2. This appears to be due to the use of maximum principal stresses in the effective notch stress method on the compression side, this stress changes both location and direction when compared to the tensile side.

\subsection{Stress calculation results and comparison}

Only relative comparisons of stress levels were given so far. In this sub-section, the stress quantities themselves and the considered stress amplitudes for the different calculations are discussed.

Figure 8 shows the stresses calculated for a Yshaped butt weld corresponding to the nominal FAT class 90 and the geometric requirements as specified

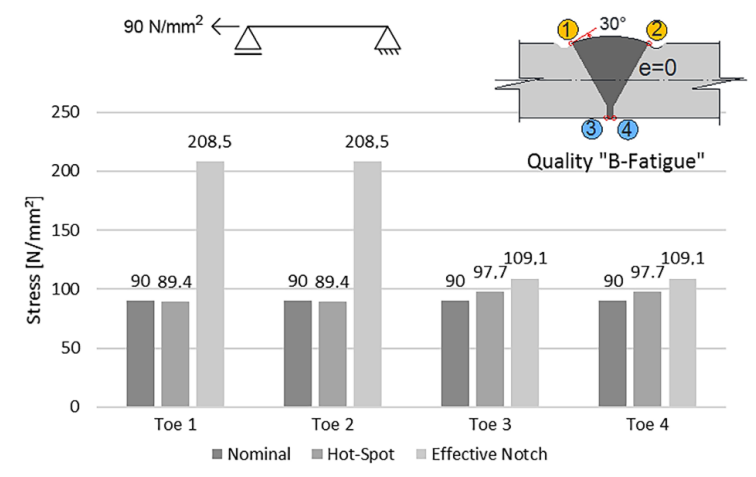

Fig. 8. Stresses in a butt weld of "B-Fatigue" quality (^ᅫnominal FAT class 90) without misalignment $(\mathrm{e}=0)$ according to the different fatigue design methods: nominal stress, structural

(hot-spot) stress and effective notch stress methods

in Table 1, with the exception of misalignment, which was omitted in this case. This calculation served the purpose of highlighting the inherent differences between the stress calculation methods, and to prove that the numerical methods generally require a specific consideration of misalignment effects.

In order to facilitate the comparison of the stress calculation results and of its relationship to the pertinent $\mathrm{S}-\mathrm{N}$ fatigue design curves, a remote (and thus, nominal) stress of $\sigma_{\text {nom }}=90 \mathrm{~N} / \mathrm{mm}^{2}$ was applied at the ends of the plates, corresponding to the value of the design S-N curve for the nominal FAT class 90. This means that, according to the traditional nominal stress approach, this detail has a design fatigue life of 2 million load cycles, with a survival probability of $95 \%$. As can be seen in Table 1 and Figure 1, the equivalent stress values for the structural (hot-spot) stress and effective notch stress methods are $\sigma_{\mathrm{hs}}=100 \mathrm{~N} / \mathrm{mm}^{2}$ and $\sigma_{\text {en }}=225 \mathrm{~N} / \mathrm{mm}^{2}$, respectively.

As can be seen in Figure 8, when misalignment is omitted the different methods do not consistently lead to these respective, fatigue life - equivalent stress values. The structural (hot-spot) stress method is already very close to the "correct" value of $100 \mathrm{~N} / \mathrm{mm}^{2}$ (which would mean the same fatigue life of 2 million load cycles as for the nominal S-N approach) at a maximum value of $97.7 \mathrm{~N} / \mathrm{mm}^{2}$ in toes 3 and 4 . The effective notch stress method, however, leads to the conclusion that the toes 1 and 2 on the broad side of the weld are more critical; in this case, the difference between the "correct" value of $225 \mathrm{~N} / \mathrm{mm}^{2}$ for the same design fatigue life as the nominal stress method is more marked, with a maximum value of $208.5 \mathrm{~N} / \mathrm{mm}^{2}$ (ratio $208.5 / 225=92.7 \%)$. 
In the following section 4.3 , the same methodology of stress calculation and comparison as shown above is used. That is, for each detail the nominal stress value that defines the Eurocode nominal stress FAT class (see Table 1) is applied at the plate ends, and the structural and effective notch stresses are calculated at the 4 weld toes.

\subsection{Comparison of fatigue life predictions}

The methodology used in section 4.2 is applied in this section to all considered butt weld geometries and various levels of imperfection and misalignment. However, the comparison is no longer carried out in terms of stresses. Instead, the fatigue life prediction, ignoring the fatigue limit $\Delta \sigma_{\mathrm{D}}$, is directly looked at and compared. This is necessary due to the need to consider additional rules of the IIW recommendation, which are discussed in the following.

As stated further above, the IIW recommendation (Hobbacher 2016, chapter 3.8.2) includes the information that stress-raising effects due to plate misalignment of 5\% are included in the FAT classes for the structural stress and effective notch stress methods. The recommendation thus states that this effect should be corrected (by a division of the stresses by a factor of $1.05)$ if misalignment is explicitly modelled in the numerical analysis for the structural stress and effective notch stress methods. This is expressed by the definition of an effective stress modification factor $\mathrm{k}_{\mathrm{m} \text {,eff' }}$, defined as follows:

$$
k_{\mathrm{m}, \mathrm{eff}}=\frac{k_{\mathrm{m}, \text { calculated }}}{k_{\mathrm{m}, \text { already covered }}}=\frac{k_{\mathrm{m}, \text { calculated }}}{1,05} .
$$

The value of $\mathrm{k}_{\mathrm{m} \text {,calculated }}$ corresponds to the ratio of the (structural hot-spot or effective notch) stresses calculated for a joint with and without misalignment, and is thus equal to the ratios $\sigma_{\mathrm{hs}} / \sigma_{\mathrm{hs}, 0}$ respectively $\sigma_{\mathrm{en}} / \sigma_{\mathrm{en}, 0}$, of Figure 7 . This rule effectively means that all stress raising effects calculated with a model with misalignment may be reduced by a division by 1.05 .

However, the IIW recommendation also states that a default or minimum value of $\mathrm{k}_{\mathrm{m} \text {,eff }}$ must always be applied to the stresses calculated for the reference model without misalignment $(e=0)$. This value varies, depending on the weld fabrication and type, and is summarized in the following Table 2.

The application of Table 2 means that, for misaligned welded joints, the value of $\mathrm{k}_{\mathrm{m} \text {,eff }}$ calculated using Eq. (2) must be checked against the default value in Table 2, and the latter must be used in design, regardless of the actual stress calculation in the misaligned configuration, if the former is smaller.

In the following graphs and figures, the results of the numerical stress calculations, modified by the above rules from the IIW recommendation when necessary, is shown for a number of different butt weld configurations and imperfection levels. The results are compared in terms of obtained fatigue life cycles $\mathrm{N}_{\mathrm{FAT}}$ calculated from the respective stresses using Eq. (3):

$$
N_{F A T}=2 \cdot 10^{6} \cdot\left(\frac{\Delta \sigma_{c}}{\Delta \sigma_{e f f}}\right)^{m},
$$

where: $\Delta \sigma_{c}-$ value of the S-N curve at $2 \cdot 10^{6}$ load cycles, valid for the respective FAT class and method; $\Delta \sigma_{\text {eff }}$ - effective value of the stress amplitude; this corresponds to the applied stress at the model extremities for the nominal stress method, and to the value of $\sigma_{\mathrm{hs}} \cdot \mathrm{k}_{\mathrm{m} \text {,eff }}$ resp. $\sigma_{\mathrm{en}} \cdot \mathrm{k}_{\mathrm{m} \text {,eff }}$ for the structural stress and effective notch stress methods, calculated at each weld toe 1 to 4 , see Figure 9; $\mathrm{m}$ - slope of the S-N curve; considered to be equal to $\mathrm{m}=3$ in all cases here.

Table 2. Consideration of misalignment through effective values of the stress raising factor $\mathrm{k}_{\mathrm{m}}$,

\begin{tabular}{|c|c|c|c|c|}
\hline Type of $\mathrm{k}_{\mathrm{m}}$ analysis & $\begin{array}{l}\text { Nominal stress } \\
\text { approach }\end{array}$ & \multicolumn{2}{|c|}{ Structural and effective notch stress approach } & \multirow{2}{*}{$\begin{array}{l}\text { Considered to apply } \\
\text { to these nominal FAT } \\
\text { classes in this paper }\end{array}$} \\
\hline Type of welded joint & $\begin{array}{c}\mathrm{k}_{\mathrm{m}} \text { already covered } \\
\text { in FAT class }\end{array}$ & $\begin{array}{c}\mathrm{k}_{\mathrm{m}} \text { already covered } \\
\text { by S-N curves }\end{array}$ & $\begin{array}{c}\text { Default / minimum value of } \\
\mathrm{k}_{\mathrm{m}, \mathrm{eff}}=\mathrm{k}_{\mathrm{m}, \mathrm{eff}, \mathrm{min}} \text { to be considered }\end{array}$ & \\
\hline $\begin{array}{l}\text { Butt joint made in } \\
\text { shop in flat position }\end{array}$ & 1.15 & \multirow{3}{*}{1.05} & $1.10^{1}$ & FAT 90 - butt weld \\
\hline Other butt joints & 1.30 & & $1.25^{1}$ & FAT 80 - butt weld \\
\hline Cruciform joints & 1.45 & & $1.40^{1}$ & $\begin{array}{l}\text { FAT } 80 \text { or } 36- \\
\text { cruciform joint }\end{array}$ \\
\hline
\end{tabular}
according to the IIW recommendation

Note ${ }^{1}$ but not more than $1+2.5 \mathrm{e}_{\max } / \mathrm{t}$, with $\mathrm{e}_{\max }=$ permissible misalignment. 


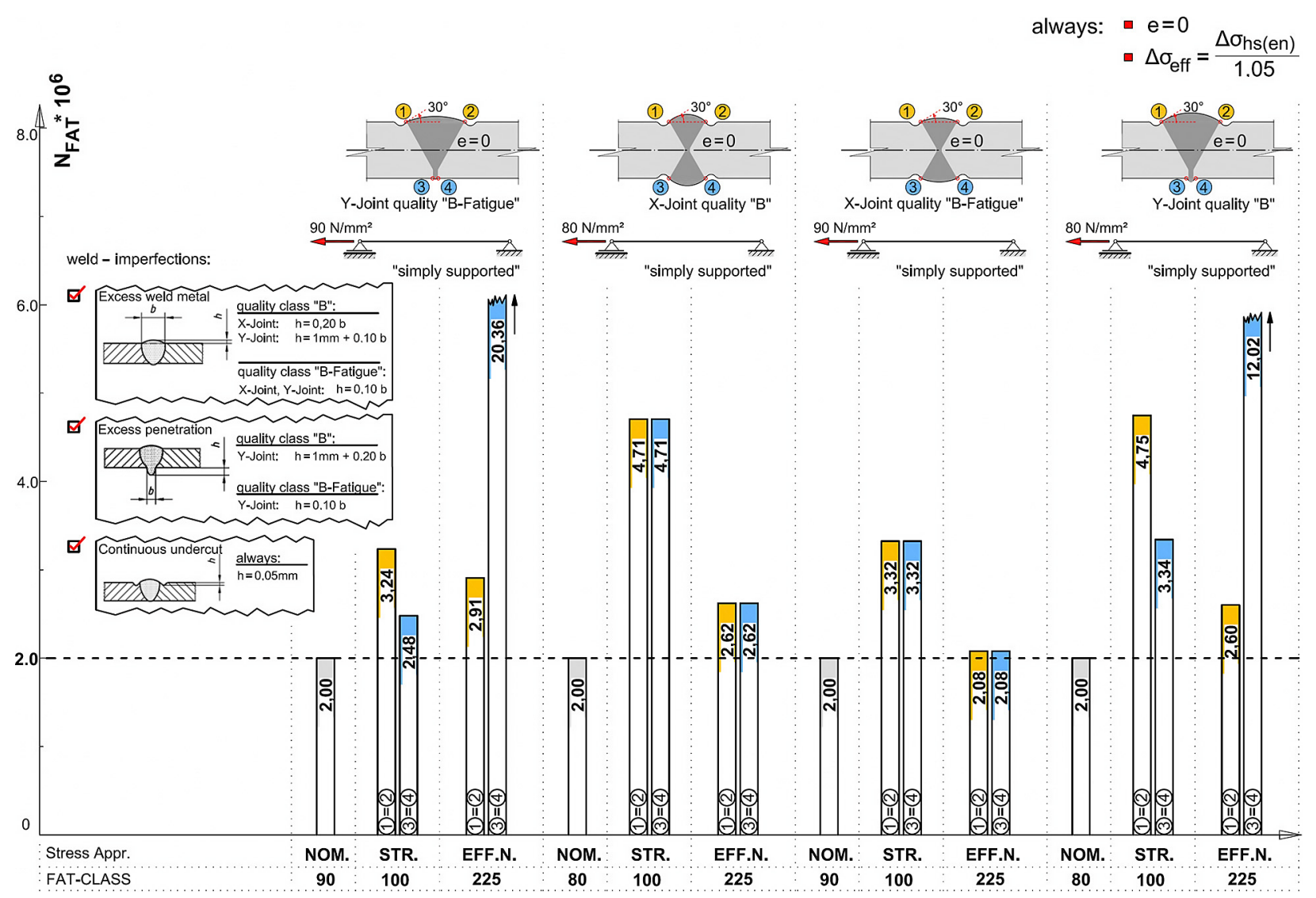

Fig. 9. Comparison of design fatigue life values for butt welds: various nominal FAT classes and weld geometries; misalignment omitted; continuous undercut considered

In Figure 9 and Figure 10, various configurations and quality levels (corresponding to different nominal FAT classes) of butt welds are considered. Misalignment is omitted in these calculations. Since a factor of $\mathrm{k}_{\mathrm{m} \text {,already covered }}$ of 1.05 is included in the structural and effective notch stress FAT classes to account for misalignment, $\Delta \sigma_{\text {eff }}$ corresponds to the calculated value of $\sigma_{\mathrm{hs}}$ resp. $\sigma_{\mathrm{en}}$, divided by 1.05. For Figure 9 , excess weld metal, excess root penetration and continuous undercut were considered, while the continuous undercut was omitted in Figure 10.

The main results are presented in the vertical bars in the figures. The numbers on top of the bars represent the calculated fatigue life values $\mathrm{N}_{\mathrm{FAT}}$. A distinction is made between the different weld toes, as indicated in the encircled numbers at the bottom of the vertical bars. Four types of butt weld are compared in Figure 9 and 10: $i$. two with "standard" quality "B" $\left(2^{\text {nd }}\right.$ and $4^{\text {th }}$ from the left), corresponding to FAT class 80 in the nominal stress approach; $i$. two with increased quality "B-fatigue" ( $1^{\text {st }}$ and $3^{\text {rd }}$ from the left), corresponding to the higher nominal stress method FAT class 90, see Table 1.
Due to the chosen stress levels and per definition, the nominal stress fatigue life is equal to 2 million load cycles. For the two numerical methods, the values of $\mathrm{N}_{\mathrm{FAT}}$ in Figure 9 and 10 (no misalignment) are consistently higher than 2 million, in some cases very significantly so. For example, the X-joint with FAT 80 / quality level " $\mathrm{B}$ " has more than twice the fatigue life of the nominal stress approach when applying the structural stress approach without misalignment, and almost 3 times the fatigue life according to the effective notch stress method. It shall be noted that, due to the power of $\mathrm{m}$ in Eq. (3), fatigue life is strongly over-proportionally sensitive to changes in stress, which explains these large discrepancies.

From the point of view of reliability of the design outcome, one must keep in mind that very simple, long-established details are studied here, for which the nominal stress method is known to lead to reliable, and statistically validated, fatigue life predictions. For this reason, the large additional fatigue life postulated in Figure 9 and 10 for the numerical methods should not be seen as a desired result of a "more advanced" method - it is instead a lack of safety, that must be ad- 


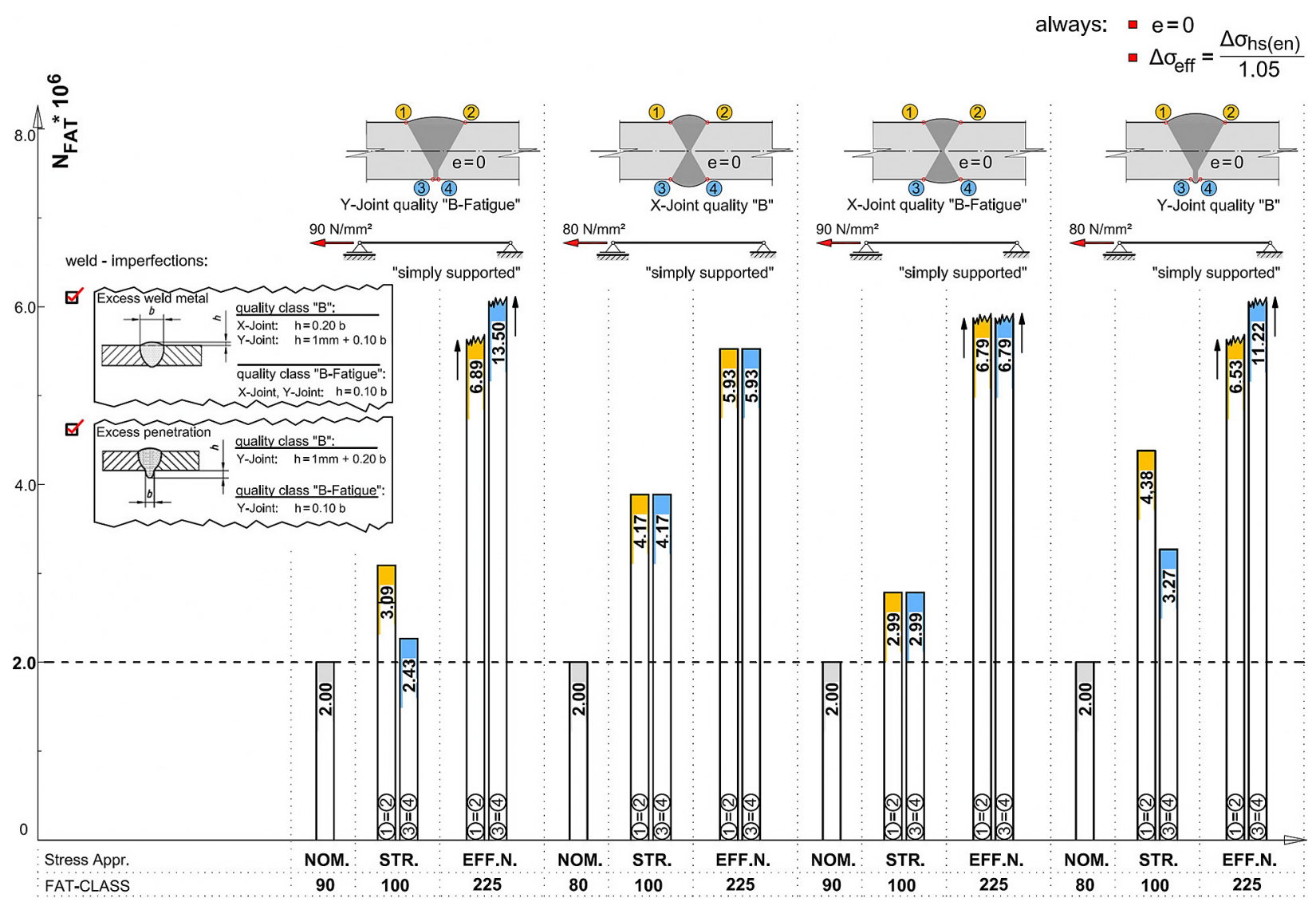

Fig. 10. Comparison of design fatigue life values for butt welds: various nominal FAT classes and weld geometries; misalignment omitted; continuous undercut omitted

dressed by including misalignment in the numerical analyses.

Misalignment is included in the calculation results shown in Figure 11 and 12. These figures show the same details as Figure 9 and 10, but in this case a misaligned configuration with the maximum permissible value of misalignment for each configuration and nominal FAT class was considered, see Table 1. Again, one figure (Fig. 11) includes the effect of a continuous undercut, while the other (Fig. 12) omits it. Since misalignment was now considered, the rule regarding a minimum / default value of $\mathrm{k}_{\mathrm{m} \text {,eff }}$ of Table 2 was now applied, as indicated in the figure. For FAT 90 / quality "B-Fatigue", this minimum value is equal to $\mathrm{k}_{\mathrm{m} \text {,eff,min }}=1.10$, while for FAT $80 /$ quality "B" it is 1.25. The fatigue life values were only calculated in the weld toes where misalignment leads to an increase of stress (the others are indicated as not relevant "N.R."). Whenever the rule concerning $\mathrm{k}_{\mathrm{m} \text {,eff,min }}$ became decisive, the fatigue life in the vertical bars is marked by an asterisk *.
The importance of this rule concerning the minimum value of the stress raising effect of misalignment is clearly visible in the figures: it applies in almost all considered cases. Through this rule, the two numerical fatigue design methods lead to safe or nearly equal results when compared to the statistically validated results of the nominal stress approach - provided that the continuous undercut is also considered. As can be seen in Figure 12, however, the omission of this weld irregularity again leads to a lack of conservatism for the effective notch stress method.

\section{Results for cruciform joints}

The same type of calculations and evaluations as described above for butt welds were also carried out for cruciform joints. As shown in Figure 3, the discontinuous plates were considered to be loaded in these calculations. When misalignment was considered, it was limited to a value of $\mathrm{e}=0.1 \cdot \mathrm{t}$ (eccentricity of the upper to the lower plate), which is lower than the maximum permissible value according to Table 1 . 
A. Taras, H. Unterweger. Numerical methods for the fatigue assessment of welded joints ...

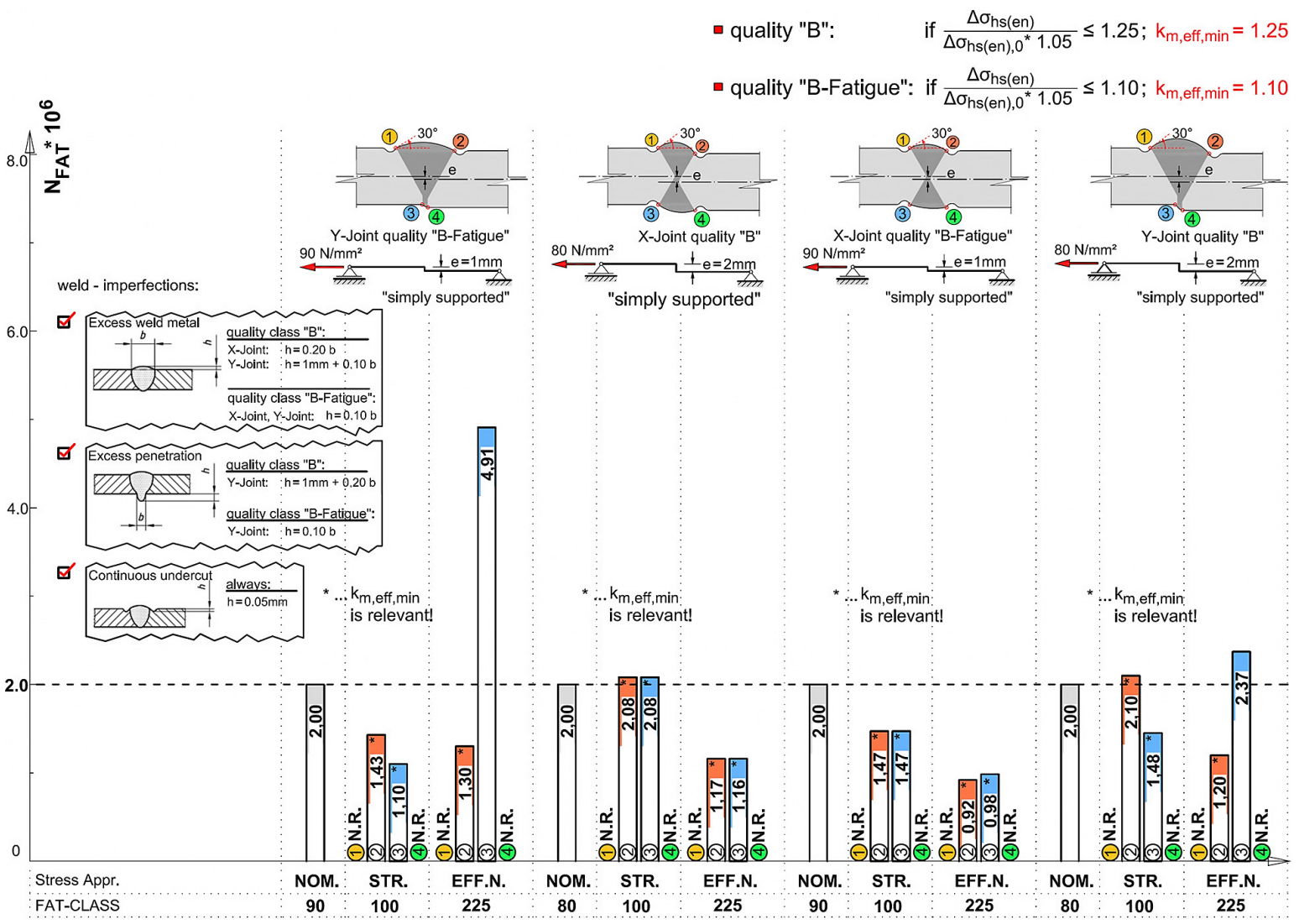

Fig. 11. Comparison of design fatigue life values for butt welds: various nominal FAT classes and weld geometries; misalignment equal to the maximum permissible value considered; continuous undercut considered

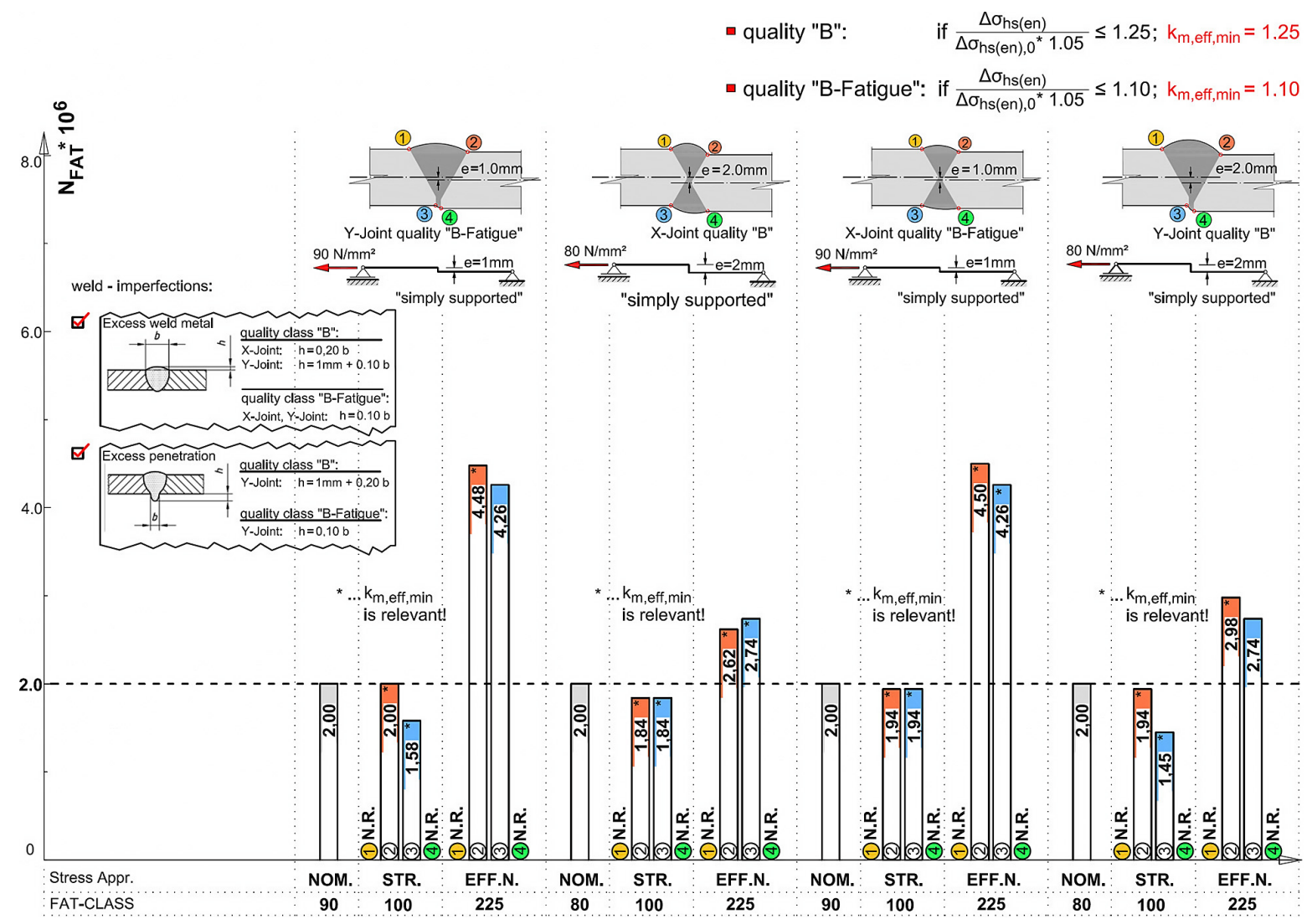

Fig. 12. Comparison of design fatigue life values for butt welds: various nominal FAT classes and weld geometries; misalignment equal to the maximum permissible value considered; continuous undercut omitted 
This was done in order to maintain some consistency with the calculations for butt welds, and to assure that $\mathrm{k}_{\mathrm{m}, \mathrm{eff} \text { min }}$ did not become relevant in all cases. This definition entailed that Note 1 in Table 2 became relevant, effectively limiting the value of $\mathrm{k}_{\mathrm{m} \text {,eff,min }}$ for the considered cruciform joint geometries to $1+2.5 \cdot 0.1=1.25$. This value was considered in the following figures when relevant.

Two different crack positions and thus nominal FAT classes must be considered in the cruciform joint: FAT 80 for a crack starting at the weld toe, and FAT 36 for root cracking (see Table 1). In order to show which crack initiation spot was predicted to be critical (i.e. has the lower fatigue life), in this case the FEM model extremities were always loaded by a stress of $100 \mathrm{~N} / \mathrm{mm}^{2}$, irrespective of the two FAT classes. Due to the sizing of the fillet weld (the throat "a" is half the size of the joined plate, on each side), the nominal stress in the fillet welds - when considered to have a "perfect" triangular geometry - was also $100 \mathrm{~N} / \mathrm{mm}^{2}$. This means that the design fatigue life values $\mathrm{N}_{\mathrm{FAT}}$ for the nominal stress approach were significantly lower than 2 million load cycles in these calculations; since only the relative comparison is of interest, this fact is of minor relevance. It must however be stated that the constant-slope S-N curves of Figure 1 were considered again, thus ignoring the fatigue limit $\Delta \sigma_{\mathrm{D}}$ in order to better illustrate the more specific differences between the single fatigue design methdods. The results for the "perfect" triangular weld geometry are given in Figure 13.

Finally, it should be pointed out that, in Figure 14 and 15 , the increased throat thickness due to the presence of a large weld convexity was also considered in the calculation of the nominal stress; this was considered to be necessary because, in fact, the weld convexity represents an increase of the throat thickness and thus an inherent reinforcement against root cracking while it represents a strong additional notch effect for toe cracking.

In Figure 13 to 15, two values of plate misalignment are considered, $\mathrm{e}=0$ and $\mathrm{e}=0,1 \cdot \mathrm{t}$. For the case with misalignment, the rule concerning $\mathrm{k}_{\mathrm{m} \text {,eff,min }}$ was applied when relevant, while for $\mathrm{e}=0$ this was not considered; in both cases, however, the stress results from the numerical calculation where reduced by 1.05 , see Eq. (2).

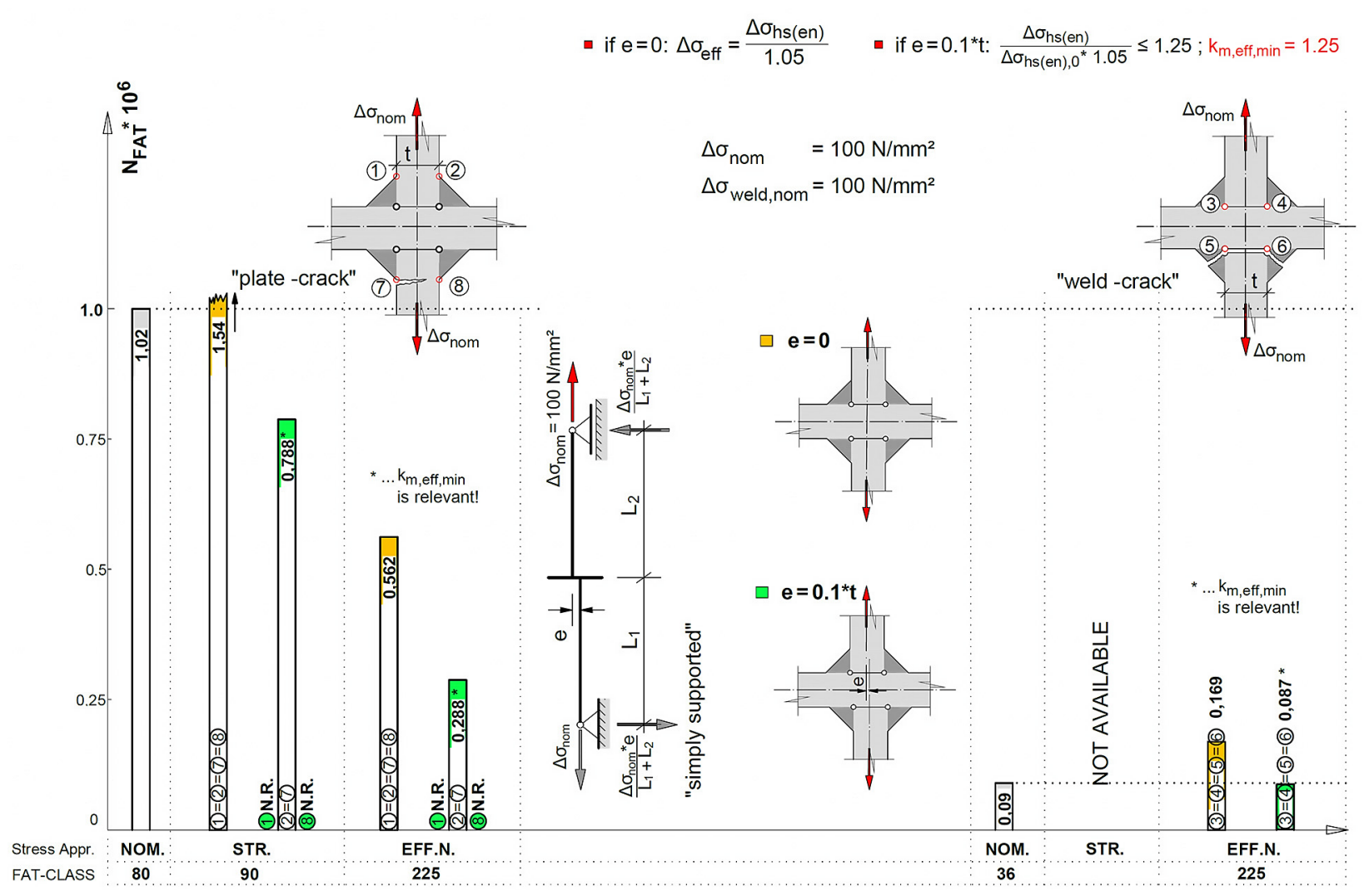

Fig. 13. Comparison of design fatigue life values for cruciform joints: FAT class for crack at weld toe and from fillet weld root; two values of misalignment considered, $\mathrm{e}=0$ and $\mathrm{e}=0,1 \mathrm{t}$; weld convexity and continuous undercut omitted 
The results in Figure 13 are valid for a cruciform joint with "perfect" fillet weld geometries, without weld convexity and without continuous undercut at the weld toes, while in Figure 14 the weld convexity up to the limit value for ISO 5817 level B was included (see pertinent box in Fig. 14). In Figure 15, a continuous undercut at the weld toes, up to the maximum permissible value, was additionally considered. The fatigue life results $\mathrm{N}_{\mathrm{FAT}}$ are plotted in the vertical bars, as before. Cracking in the plates (from the weld toes) is distinguished from cracking from the root. In the latter case, no structural stress apprach FAT class is specified in the IIW recommendation or Eurocode 3 thus no calculation was possible.

The fatigue life predictions in Figure 13 to 15 confirm and reinforce the findings of section 4 , valid for butt welds. For cruciform joints, it is again apparent that the various methods lead to significantly diverging fatigue life predictions. In contrast to the previous results, however, it is now remarkable that the effective notch stress method consistently leads to much lower fatigue life values than the nominal and structural stress methods for the considered geometries - partic- ularly for toe cracking in strongly imperfect fillet welds and when misalignment is accounted for. The structural stress approach is only applicable for toe cracking, and is accurate when misalignment is accounted for as specified in the IIW recommendation. The omission of misalignment would however be strongly unconservative for this method.

\section{Discussion and research outlook}

The results presented in sections 4 and 5 highlighted the discrepancies that may be found when applying and comparing the different traditional and numerical fatigue design methods of current standards and the literature to standard welded joints in steel structures. Due to the simplicity and the strong statistical validation of the studied details, the nominal stress approach should be seen as the relevant "benchmark" for the application of the numerical methods - which is contrary to the often repeated opinion that the numerical method, due to its larger degree of computational sophistication, must be somehow "more correct". The lack of conservatism observed in some applications of

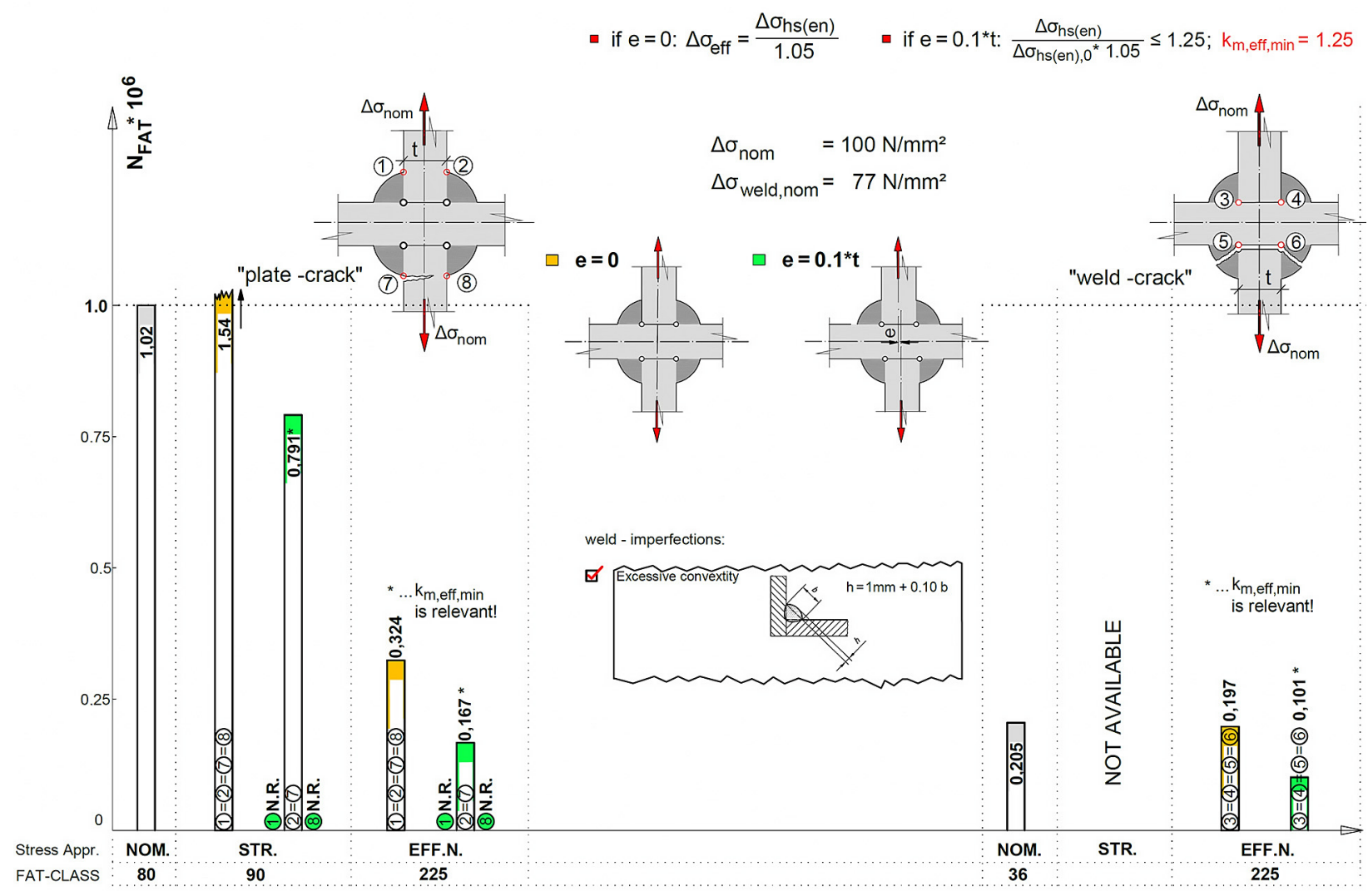

Fig. 14. Comparison of design fatigue life values for cruciform joints: FAT class for crack at weld toe and from fillet weld root; two values of misalignment considered, $\mathrm{e}=0$ and $\mathrm{e}=0.1 \mathrm{t}$; maximum permissible weld convexity considered;

continuous undercut omitted 


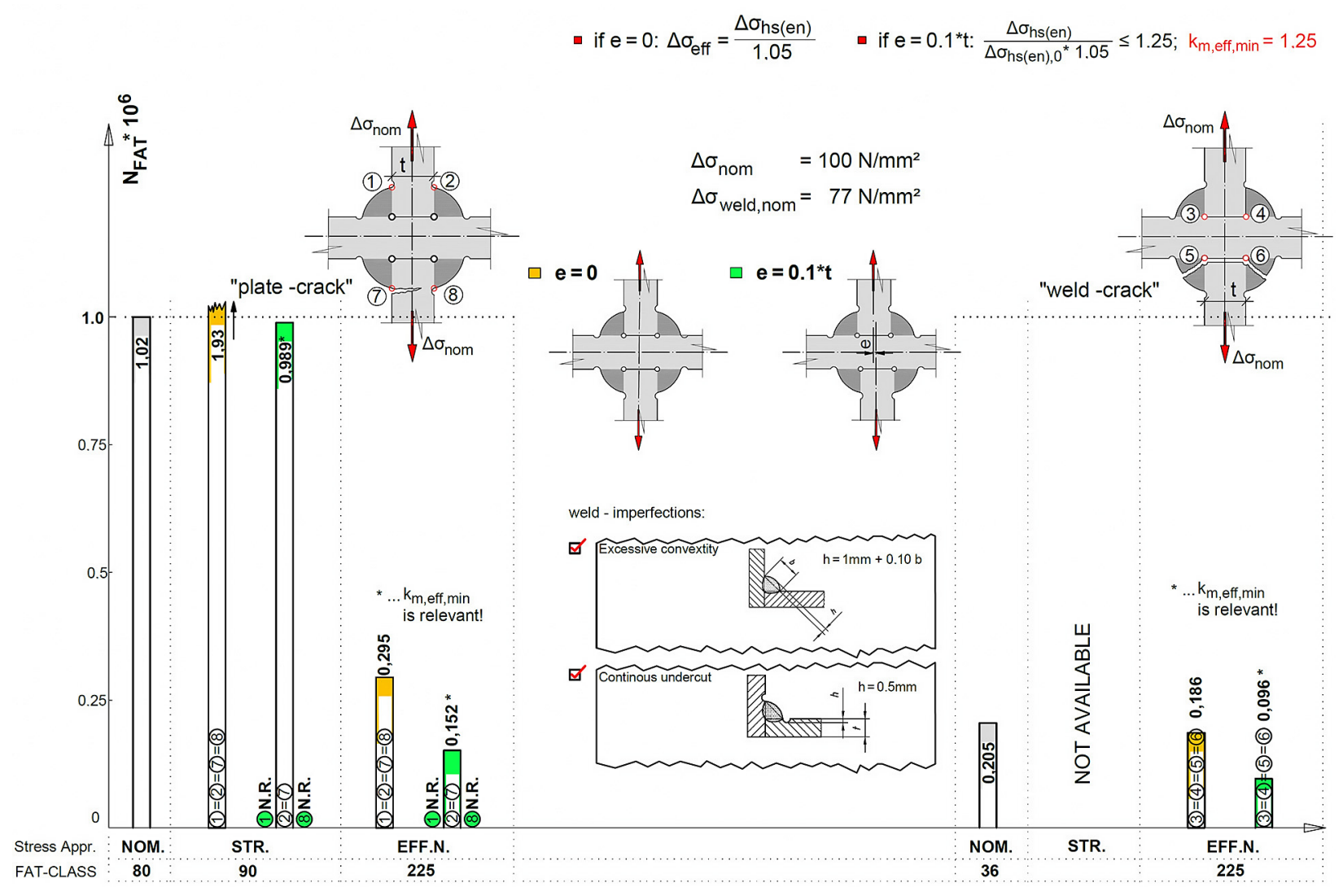

Fig. 15. Comparison of design fatigue life values for cruciform joints: FAT class for crack at weld toe and from fillet weld root; two values of misalignment considered, $\mathrm{e}=0$ and $\mathrm{e}=0.1 \mathrm{t}$; maximum permissible weld convexity considered and continuous undercut considered

the structural stress and effective notch stress methods highlight the need for a more thorough study of the application range and the necessary inclusion of various geometric imperfections in the numerical analyses, before a satisfactory level of safety may be guaranteed for complex applications in important civil engineering works. In particular, the results in sections 4 and 5 confirm that the effect of misalignment must be generally included in both the structural stress and effective notch stress methods. This is currently not made clear in Eurocode 3, and generally requires more guidance from design recommendations and codes. In a recent graduate thesis supervised by the authors (Baltali 2014), additional effects were highlighted: they include the mesh sensitivity of the effective notch stress method for strongly imperfect weld toes, as well as the difficulty in calculating structural stresses in these cases.

Future research should furthermore focus on the reliability of the numerical design rules. The results of the present study have shown a very large scatter in the fatigue life predictions of the effective notch method when compared to validated S-N curves for standard details, based on the nominal stress approach. Since the use of a single FAT class for the effective notch stress method invariably must cover these differences for all kinds of structural details and applications, the applicability of this concept, in its current form, in the context of the strict reliability requirements of the Eurocode design codes should be checked with particular care.

\section{Summary and conclusions}

In this paper, a study was presented in which two standard welded joints (butt welds between plates of equal and unequal thickness; T-joints with fillet welds) were analysed with the help of the structural stress and the effective notch stress approach, considering various levels of geometric imperfection up to the tolerance limits, and the resulting fatigue life predictions were compared to the nominal stress approach predictions. Since the nominal stress approach curves are based on comprehensive, reliable statistical data of full-scale fatigue tests, as well as desired survival probabilities for these known, standard cases, this methodology allows one to determine the correct application of the numerical methods to cases with geometric imperfections. 
The results presented in this paper highlighted persistent discrepancies in the fatigue life predictions according to the various methods. The need to consider specifically the possibility and magnitude of plate misalignment in the numerical models for the structural stress and effective notch stress methods was highlighted through the considered examples - in many cases, the numerical calculations would otherwise lead to overly optimistic estimations of fatigue life. On the other hand, some cases were found where the numerical methods are vastly more conservative than the traditional approach, even when plate misalignment is omitted. It is thus clear that the numerical methods currently suffer from a very variable level of reliability. The results and discussions presented in this paper may thus be used as a basis for a pertinent refinement of design recommendations for these methods.

\section{Acknowledgements}

The authors would like to acknowledge the numerical and graphical work carried out by Mr. Gürel Baltali, MSc. and Mr. Christoph Derler, BSc. Their contribution to the completion of this research work was very valuable and much appreciated.

\section{Disclosure statement}

The authors declare that they do not have any competing financial, professional, or personal interests and did not receive undeclared contributions from other parties during the elaboration of this research work.

\section{References}

Aygül, M.; Bokesjö, M.; Heshmati, M.; Al-Emrani, M. 2013. A comparative study of different fatigue failure assessments of welded bridge details, International Journal of Fatigue 49: 49-62. https://doi.org/10.1016/j.ijfatigue.2012.12.010

Baltali, G. 2014, The effect of misalignment on the stress field and fatigue strength of welded joints: Master's thesis. Graz University of Technology, Institute for Steel Structures, Graz, Austria.

EN 1090-2:2009. Execution of steel structures and aluminium structures. Technical requirements for steel structures. CEN, Brussels.

EN 1993-1-9: 2005. Eurocode 3: Design of Steel Structures - Part 1-9: Fatigue. CEN, Brussels.

Fricke, W. 2010. Guideline for the fatigue assessment by notch stress analysis for welded structures. International Institute of welding, IIW Doc. XIII-2240-08/XV-1289-08.

Hobbacher, A. 2016. IIW Recommendations for the fatigue design of welded joints and components. $2^{\text {nd }}$ ed. International Institute of Welding, Villepinte (FR).

https://doi.org/10.1007/978-3-319-23757-2

ISO 5817:2014. Welding. Fusion-welded joints in steel, nickel, titanium and their alloys (beam welding excluded). Quality levels for imperfections. International Organization for Standardization, Geneva $(\mathrm{CH})$.

Lotsberg, I. 1998. Stress concentration factors at circumferential welds in tubulars, Marine Structures 11(6): 207-230. https://doi.org/10.1016/S0951-8339(98)00014-8

Lotsberg, I. 2006. Fatigue design of plated structures using finite element analysis, Journal of Ships and Offshore Structures 1(1): 45-54. https://doi.org/10.1533/saos.2005.0006

Maddox, S. J. 1991. Fatigue strength of welded structures. Cambridge: Abington Publishing.

Radaj, D.; Sonsino, C. M.; Fricke, W. 2006. Fatigue assessment of welded joints by local approaches. 2 ed. Cambridge: Woodhead Publishing. https://doi.org/10.1533/9781845691882

Sonsino, C. M. 2009. A consideration of allowable equivalent stresses for fatigue design of welded joints according to the notch stress concept with the reference radii $\mathrm{r}_{\text {ref }}=1.00$ and $0.05 \mathrm{~mm}$, Welding in the World 53(3): R64-R75. https://doi.org/10.1007/bf03266705

Andreas TARAS, Univ.-Prof. Dipl.-Ing. Dr techn. IWE. Born in 1980 in Bolzano (Italy), civil engineering studies at TU Vienna and Graz University of Technology (TUG), Austria; PhD at the Institute for Steel Structures of TUG in 2010; Assistant Professor 2012-2016; since 04/2016 Full Professor at Bundeswehr University Munich, Germany - Institute of Structural Engineering, Chair of Steel Structures.

Harald UNTERWEGER, Univ.-Prof. Dipl.-Ing. Dr techn. Born in 1964 in Klagenfurt (Austria), civil engineering studies, PhD and habilitation treatise at Graz University of Technology (TUG), Austria. Full Professor and Head of the Institute for Steel Structures at TUG since $07 / 2011$. 